\title{
AS UNIDADES PLIOCÉNICAS E QUATERNÁRIAS NO ESPAÇO DO BAIXO MONDEGO (UMA PERSPECTIVA DE ORDEM)
}

A. FERREIRA SOARES *

Abstract

Resumo

\begin{abstract}
Pliocene and Quaternary Units in the Lower Mondego (Portugal) - The analysis of the relations between the quaternary deposits in the Baixo Mondego, as well as their individualisation from others considered as Pliocene, still suffer from insufficient reference marks necessary to guarantee equivalencies. The limit is now considered to be in the concert of the Cruz de Morouços Complex, where the Antanhol Formation (= Barracão Group, Upper Pliocene) and the Espírito Santo Conglomerate, equivalent to the Gordos Conglomerate (Lower Pleistocene), succeed to each other. From the Pleistocene assemblage and beside the deposits directly associated to the evolution of Mondego (Ameal-Santo Varão and TentugalGabrielos deposits), the deposits revealing upper littoral environments stand out, as the Arazede Sandstone, the Quiaios Sandstone, others deposits directly related with the Cabo Mondego morphogenesis, the Farol Deposits, fossiliferous and possibly from the Lower to Middle Pleistocene and the Murtinheira Deposits from the Upper Pleistocene. In turn the Condeixa Tuffs, with an accommodation space of $24 \mathrm{Km}^{2}$, show an ordered succession of facies (Conglomerates $-\mathrm{Cg}$; yellow mud $-P a$, tuffs - $T a$ and $T c$; grey mud with Lymnea $-P c$ ) and an extended age from the Pleistocene (with Elephas antiquus and Hippopotamus incognitus in the base) possibly around the $400 \mathrm{Ka}$, to the Holocene (facies Pc with roman archaeological remains).
\end{abstract}

Key-words: Lower Mondego, Pliocene, Quaternary, Antanhol formation, Espírito Santo formation, Gordos conglomerate, Arazede sands, Terraces, Tufos de Condeixa e Tufos de Avenal.

A análise das relações entre os depósitos quaternários no espaço do Baixo Mondego, bem como a sua individualização daqueles outros tidos por pliocénicos, sofrem, ainda hoje, de insuficientes pontos de referência capazes de garantirem equivalências. O limite, foi agora julgado no concerto do Complexo da Cruz. de Morouços, onde se articulam a Formação de Antanhol (= Grupo de Barracão, Pliocénico Superior) e o Conglomerado de Espírito Santo, equivalente do Conglomerado de Gordos (Plistocénico inferior). Do conjunto plistocénico e para além dos depósitos associados directamente à evolução do Mondego (Depósitos de Ameal-Santo Varãoe Tentúgal-Gabrielos), destacam-se ainda os tradutores de ambientes litorais superiores, como as Areias de Arazede e as Areias de Quiaios, para além daqueles outros associados directamente à morfogénese do Cabo Mondego, como o Depósito do Farol, fossilífero e possivelmente do Plistocénico inferior a médio, e o Depósito da Murtinheira, já do Plistocénico superior. Por sua vez os Tufos de Condeixa, com uma área de acomodação cerca dos $24 \mathrm{Km}^{2}$, apresentam uma articulação ordenada de fácies (conglomerados $-C g$; pelitos amarelos $-\mathrm{Pa}$; tufos $\mathrm{Ta}$ e $T c$; pelitos cinzentos com Lymnaea -Pc) e uma idade estendida do Plistocénico (na base com Elephas antiquuse Hippopotamus incognitus ), talvez a rondar os $400 \mathrm{Ka}$, até ao Holocénico (fácies Pc com restos arqueológicos romanos).

Palavras-chave: Baixo Mondego, Pliocénico, Quaternário; Formação de Antanhol, Formação de Espírito Santo, Conglomerado de Gordos, Areias de Arazede, Terraços fluviais e litorais, Tufos de Condeixa e Tufos de Avenal.
Quando pretendemos dar conta do que se tem vindo a escrever, vai para pouco mais de um século, sobre os depósitos mais recentes e tidos por quaternários no Baixo Mondego (ALMEIDA et. al., 1990), deparamos sempre com dificuldades advindas de incontinuidades espaço-temporais. Essas mesmas que nos levaram a admitir que «[...] as coisas da estratigrafia do Quaternário em Portugal ainda estão como estão porque são assim; porque poucos ainda as olham; porque ainda nos escapam as inconfidências dos zeros [...]» (SOARES, 1993, p. 371).

De um modo geral e em paisagens de suportes mobilizáveis como os do Baixo Mondego, as dificuldades de leitura resultam quer de mimetismos produzidos por clivagens naturais \{Calhaus de Cabeços; RIBEIRO \& PATRÍCIO, 1943), quer também por obriga- tórias despredagens consequentes aos arroteamentos. Com o primeiro, preso a reconfigurações de vertentes, associam-se volumes mais ou menos importantes de depósitos areno-cascalhentos, policêntricos e em «trânsito» (coluviões). Com o segundo constroem-se máscaras que inseguram as leituras das formas, dos aplanamentos e também dos depósitos.

Mas o problema maior ao entendimento das metamorfoses que os próprios depósitos espelham está ainda na falta de argumentos paleontológicos e/ou arqueológicos suficientes a juízos cronostratigráficos, ou mesmo na falta de orientações geocronológicas. Apesar dos esforços na identificação dos depósitos (MARQUES, 1997), os quadros síntese continuam a reflectir descoradas ideias cronostratigráficas, servidas, quase sempre, por termos importados da Europa

\footnotetext{
* Departamento de Ciências da Terra, Universidade de Coimbra, tel.: 239 823022; fax: 351-239-837711. (PRAXIS XXI - Proj. 2/2.1/CTA - 156/94)
} 
alpina e usados dentro de pressupostos de raiz glacio-eustática - -O eustatismo não deve ser desatendido no ordenamento destes depósitos, sobretudo numa fachada oceânica, onde o comando exorreico tem excelência. Mas a movimentação geodinâmica duma rede hidrográfica é ditada também por outros factores, dos quais realçamos, pelas leituras que têm sido feitas aos traçados de algumas das nossas linhas de água, a tectónica e o clima» (SOARES; ob. cit., p. 368). Mesmo nos quadros que ultimamente foram desenhados e por onde já perpassam tentames alostratigráficos (SOARES et. ai, 1992, 1993) guardam-se ainda ideias com laivos altitudinais. E isto talvez porque a própria síntese das modificações tectónicas não ganhou suficiente ênfase para outros reequacionamentos de depósitos que, e por primeira característica, têm a sua própria incontinuidade. Ou talvez pelo remanescente duma ideia cuja pragmática excluía, ou relegava para outro plano, a importância da tectónica (DAVEAU, 1993). Seja como for, o problema parece voltar ao privilégio de esquemas regionais tectono-climáticos, ajustados à importância relativa das fases ana e cataglaciares. E esta tendência é tanto mais apetecível, quanto é certo estarem a dimensão e posição das unidades morfológicas quaternárias da plataforma continental na dependência dos efeitos tectónicos (VANNEY \& MOUGENOT, 1981)

A definição de qualquer limite estratigráfico é um problema delicado - primeiro nas preocupações dos estratígrafos. Não será pois de estranhar, e entre nós, as tentativas para um limite entre depósitos «marcadamente» terciários, de outros quaternários. Nem tão pouco podemos estranhar o carácter transitório e regional do(s) limite(s) em depósitos ainda azoicos, e que só recentemente começaram a beneficiar de outras técnicas para ordenamentos. É neste jogo de aproximações que justificamos problemas como o do Vilafranquiano, nascido praticamente à capa daquele outro das rañas; ou mesmo do Calabriano nas perspectivas tanto de ZBYSZEWSKI (1958), como de TEIXEIRA (1948, 1979). Desse mesmo jogo farão ainda parte as justificações para a introdução da sigla PQ (Plio-Quaternário) nas cartografias geológicas (REBELO, 1993), bem como o uso de «complexos», mais ou menos inexpressivos, como o de Barracão (CARVALHO et. aí, 1972; BARBOSA, 1983, 1995; CACH ÃO, 1990, 1995; CARVALHO, 1998) ou aquele outro da Cruz de Morouços (= "Conglomerados de Morouços», TEIXEIRA, 1952; SOARES \& REIS, 1984; SOARES, 1995), imediatamente a sul de Coimbra. Quanto ao primeiro, sabemos ser ele expressão de um grupo de unidades (Grupo do Barracão) do Pliocénico Médio e/ou Superior (CARVALHO, 1972; DINIZ, 1984; CACHÃO, 1995). Quanto ao segundo, definido na região de Cruz de Morouços, Antanhol, Espírito Santo, Brejo e Aeródromo de Cernache (folha 241 ; esc. 1/25.000; Serv. Cart. Exército; 1993), apresenta uma organização comparável (fig. 1), com uma unidade inferior (Formação de Antanhol = Conglomerado de Antanhol e Espírito Santo + Argilas negras $e$ areias; SOARES, no prelo) espelhando o Grupo de Barracão, mas com uma espessura estimada não além dos $20 \mathrm{~m}$; e outra superior descontínua, essencialmente conglomerática, por vezes com grandes rebolos de grés e/ou conglomerados silicificados (macroscopicamente semelhantes ao «Grés do Buçaco») e a altitudes que variam entre os $210 \mathrm{~m}$ na Cruz de Morouçose os $118 \mathrm{~m}$, mais a ocidente, Entre Tremoçais. É esta última unidade, a Formação de Espírito Santo (= Conglomerados de Picoto e Espírito Santo, SOARES, no prelo), cuja espessura máxima rondará os $12 \pm 3 \mathrm{~m}$, que confere o carácter conglomerático atribuído ao Complexo.

A sul, na região de Pombal, sobretudo a ocidente do Rio Arunca, o Conglomerado de Estevães, que, «conjugado» com os Conglomerados de Ranha, compõem, no entender de CARVALHO (1998), a fase P4 de Teixeira, poderá ser equivalente da Formação de Espírito Santo.

Outros depósitos equivalentes, ou como tal considerados, têm vindo a ser descritos no espaço do Baixo Mondego, normalmente a altitudes superiores a $120 \mathrm{~m}$ e, quase sempre, com grandes rebolos de grés e/ou conglomerados silicificados. Na margem esquerda do Rio podemos referir os depósitos peliculares (espessuras máximas não superiores a 2-3 m) do Alto da Serra e Onofre Branco, a rondarem os 100-120 m de altitude. Possivelmente ainda dentro deste cortejo, pelo menos em termos de expressão lítica, pois que em cota fica entre os 80-90 m, está o depósito conglomerático de $\mathrm{S}$. Tiago, com espessura cerca de 3 a $4 \mathrm{~m}$. Tenha-se em atenção que depósitos tidos por equivalentes foram também descritos para a região de Soure, onde, convergentes sobre o diapiro, atingem cotas de 50-80 m. (SOARES \& REIS, 1984).

$\mathrm{Na}$ margem direita do Mondego sobressaiem os Conglomerados de Gordos que assentam em descontinuidade sobre areias amarelo-acastanhadas, finas a muito finas, sub-maturas a maturas, com muito raro seixo e micáceas. Elas têm sido paralelizadas com as Areias de Cordinha (BARBOSA et ai, 1988; = Areias Finas de Mala, DINIS, no prelo), equivalentes do Arenito de Carnide do Grupo de Barracão. Em Gordos - Casais do Murteiro - Charneca, a oriente da Vala de Água (folha 229; esc. 1/25.000; Serv. Cart. Exército) e a altitudes a rondar os $120 \mathrm{~m}$, eles correspondem a um corpo de 3 a $6 \mathrm{~m}$ de espessura máxima, areno-conglomerático, amarelo-acastanha-do, submaturo a imaturo, e, localmente na base, com grandes rebolos de grés e/ou conglomerados silicificados (fig. 2).

A identidade que temos admitido entre os Conglomerados de Gordos e os conglomerados da plataforma 

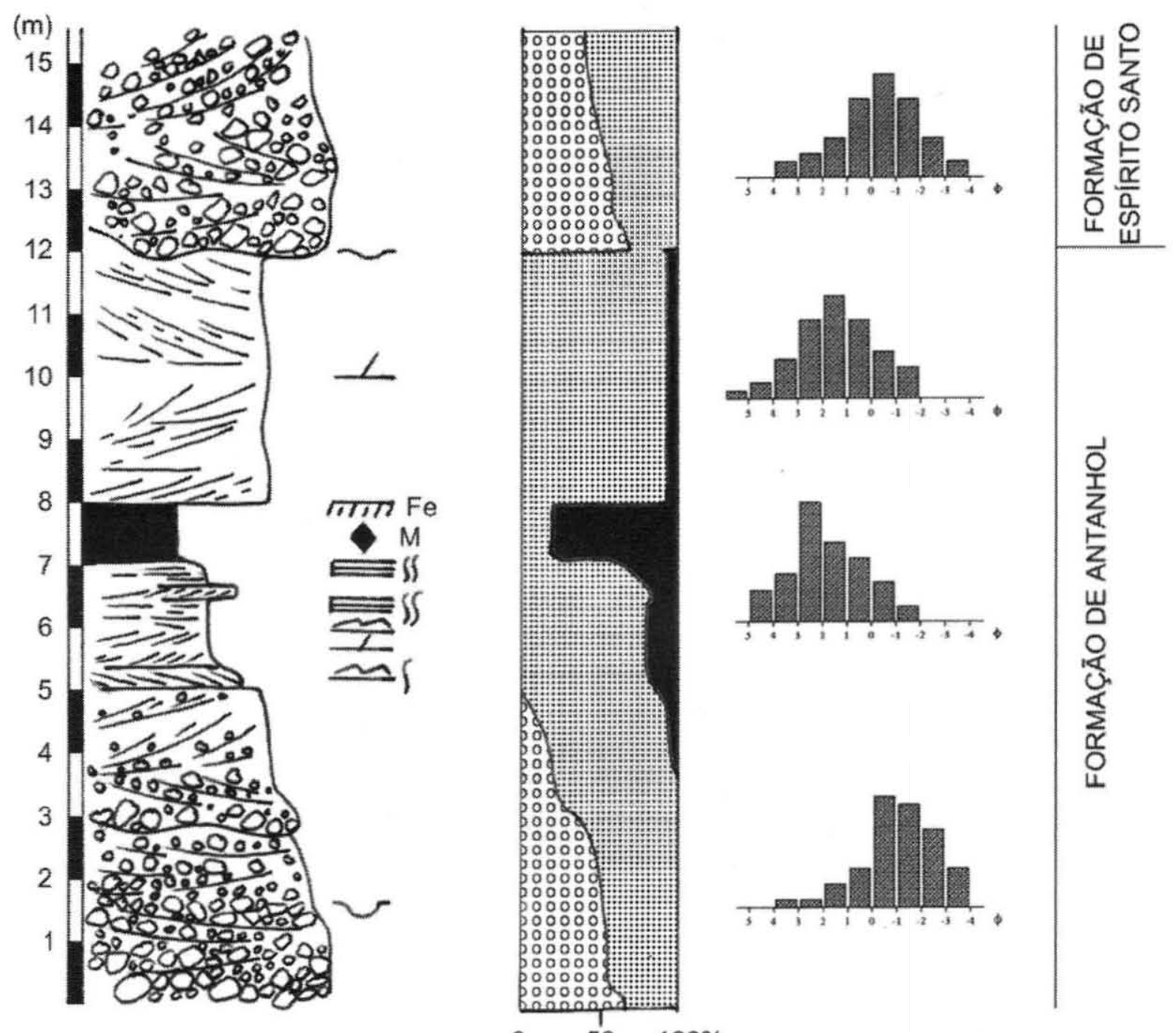

— Descontinuidade

III7 $\mathrm{Fe}$ Descontinuidade; crosta férrica

— Laminação paralela à estratificação

M Marcas de ondulaçăo

1 Estratificação obliqua

Estratificação em ventre

Bioturbação

- Fragmentos de carvão

M Micas
Eelito $(<0,125 \mathrm{~mm})$

A:-i:i: Areia $(>0,125 \mathrm{~mm})$

$\because 0:$ Seixo + Calhau

Fig. 1 - Perfil de Antanhol (Vale Ficalho).

Fig. 1 - Antanhol cross-section (Vale Ficalho). 


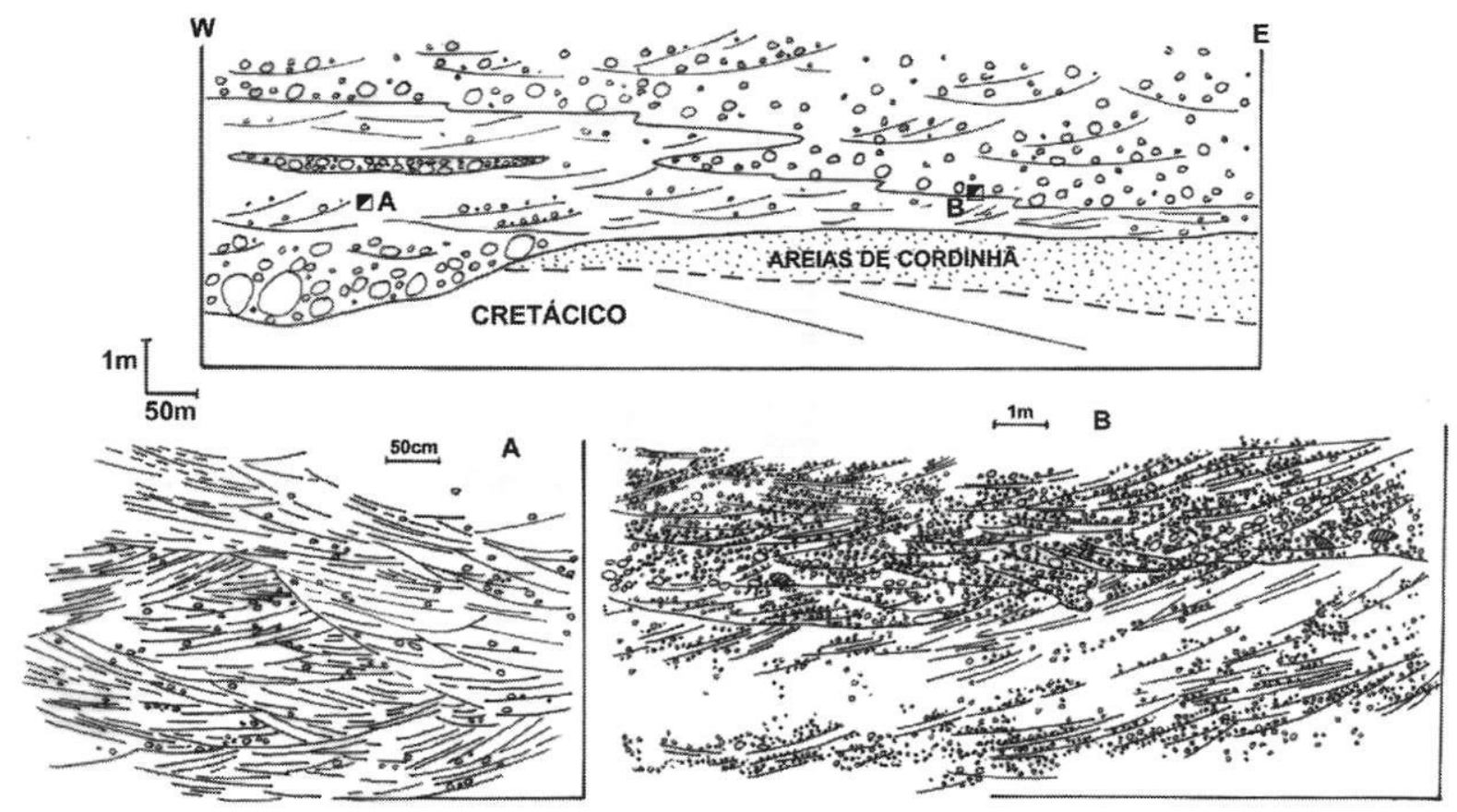

Fig. 2 - Conglomerados de Gordos. Aspectos da estratificação.

Fig. 2 - Gordos conglomerate. Bedding examples.

de Santa Luzia - Carqueijo, a norte de Coimbra, é hoje, com os trabalhos de DINIS (inf. oral) difícil, dado o carácter heterolítico destes últimos (= Areias $e$ Conglomerados de Carqueijo; DINIS, no prelo). Outro tanto parece subsistir quando encaramos a possibilidade de enquadramento dos depósitos que, em pequenas manchas, surgem na frente ocidental da Serra do Buçaco, atingindo os $230 \mathrm{~m}$ de cota. Com grandes rebolos acanalados de «Grés do Buçaco», por vezes embalados numa matriz areno-cascalhenta amarelada e donde sobressaiem pequenos seixos redondos («bichouro»), eles foram integrados por TEIXEIRA (1979) na sua fase P4, do topo do Pliocénico. Contudo, temos para nós que a leitura destes depósitos não deve ser adicionada àquela outra das Areias de Chã da Mata (possível equivalência com o Grupo de Barracão ?; SOARES, no prelo), mas talvez com os depósitos associados ao «nível da Serra da Vila» (DAVEAU, 1986) e que, no Maciço Marginal, junto a Coimbra, estarão representados pelo conglomerado a sul de Vale de Açor, a $230 \mathrm{~m}$ de altitude (SOARES et ai, 1985).

Dentro deste quadro geral de possibilidades, sem dúvida ainda hoje complexas, não nos tem parecido despiciendo olhar a deformação que afecta o conjunto destes depósitos, talvez de um Plistocénico antigo, como correspondente aquela outra da Serra da Vila. E se assim for, não podemos olvidar que para DAVEAU (ob. cit.), os sedimentos da Serra da Vila e seus correlativos nas «bacias de Lousã e Arganil» serão dum Vilafranquiano superior, anteriores a $1 \mathrm{Ma}$, mas sempre posteriores ao Grupo de Barracão e correlativos das Areias de Chã da Mata.

Em suma, o problema do limite regional entre o Pliocénico e o Plistocénico não é, como os problemas de todos os limites, fácil, independentemente da escala a que forem analisados. Neste caso concreto e no espaço do Baixo Mondego, a ele associa-se lacuna, dimensionada localmente por «falta» de parte representativa do Grupo Barracão (este apenas está bem representado na área diapírica de Soure pelo Grés argiloso com lignitos de Alencarce; SOARES \& REIS, 1984), como, ainda pela possibilidade de não haver total equivalência entre os diversos depósitos aqui uniformizados num Plistocénico antigo.

Analisado que foi o problema relativo às unidades do limite entre aquelas que são tidas como pliocénicas, e as outras dum possível Plistocénico inferior, acrescentado ainda pelas características desse mesmo limite e tudo no contexto do Baixo Mondego, colocam-senos agora outras questões respeitantes aos significados dos depósitos, ainda plistocénicos, mais recentes e lidos, dum modo geral, como «terraços fluviais e litorais» ou, tão só, como sedimentos de «praias e de terraços fluviais».

Em trabalhos anteriores (SOARES et ai, 1986; 1989; 1992; 1993 e 1998) dedicámos especial atenção 
aos depósitos fluviais e sua organização no contexto geral do Baixo Mondego e, no particular, do sector morfostrutural entre o Campo do Golão (ou Bolão) a montante, e Montemor-o-Velho a juzante. E, na consequência, analisámos também aqueles outros coluviais e/ou fanglomeráticos, presos das transformações correlativas observadas no subsistema das vertentes. Estão neste último caso não só as Areias vermelhas de Zouparria is.s.), como também as Areias vermelhas do Ingote, mais antigas e deformadas (CARVALHO, 1948; 1949; SOARES et ai, 1985, 1990; CUNHA et ai, 1996).

Dum modo geral, os depósitos essencialmente fluviais têm vindo a ser reequacionados em termos de: 1) Depósitos de Ameal - Santo Varão, mais antigos, bem representados na margem esquerda e normalmente a altitudes de 40 a $50 \mathrm{~m}$; 2) Depósito de Tentúgal ou Depósito de Tentúgal-Gabrielos (fig. 3). É contra este último depósito, onde se lê uma articulação sequencial de fácies Gt-St, Sr-Fsc, Fm (C) (SOARES et ai, 1998), que se define o corpo aluvionar do Mondego. A sua idade, e sempre no jogo das probabilidades, tem sido considerada como equivalente daquela do areno-pelito cinzento, imaturo e fossilífero da Mealhada. Tendo em atenção as conclusões de CARDoso (1993), o «depósito da Mealhada» poderá corresponder a um «interstadio do Riss», se não mesmo a um interglaciário (Mindel-Riss?), a uma época de clima temperado húmido. Seja como for, a verdade é que não há ainda elementos capazes de nos fixarem um «tempo», e a dezena de peças acheulenses até hoje encontradas no «terraço de Tentúgal», associadas a fácies conglomerática, apresentaram-se roladas.

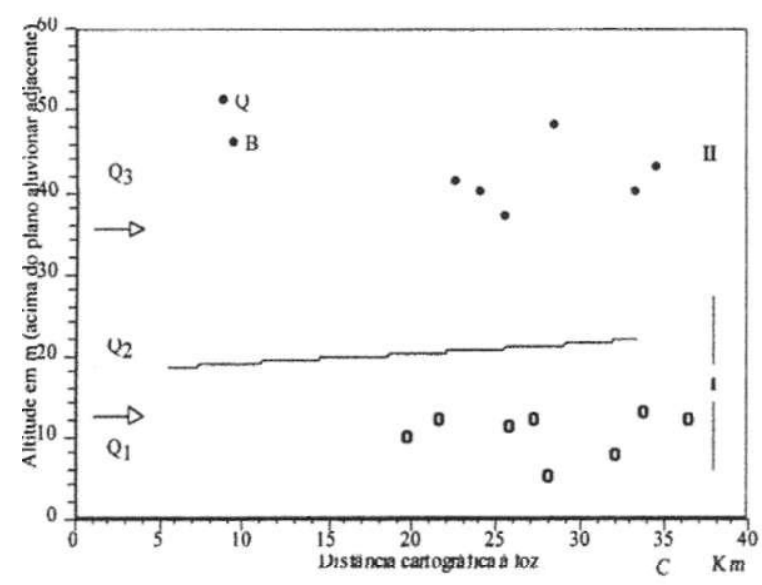

Fig. 3 - Projecção de superficies de terraço fluvial no espaço do Baixo Mondego. I - Depósito de Tentúgal-Gabrielos; II - Depósito de Ameal-Santo Varão; Q - Quinta da Colada; B - Barreira; FF - Figueira da Foz; C Coimbra; Q1 - Terraço inferior (15 metros); Q2 Terraço médio (30 metros); Q3 - Terraço superior (50 metros) (in Ribeiro \& PATrícIo, 1943).

Fig. 3 - Fluvial terraces in the Lower Mondego valley (in RIBEIRO \& PATRÍCIO, 1943).
O mesmo quadro geral de indefinições ressalta quando nos confrontamos com os sedimentos das «praias levantadas». Basta para isso analisarmos o corpo atribuído às Areias de Arazede (SOARES, 1966; BARBOSA et ai, 1988) que, e num sentido global, corresponde a arcosarenitos grosseiros a muito grosseiros, submaturos, entrecruzados, amarelo-acastanhados e ricos em seixo e calhau $(28 \pm 10 \%)$ de quartzo e quartzito redondos e com esfericidade baixa dominante. Definido na região de Arazede-Amieiro, elas aproximam-se daquelas que, mais a norte, afloram em Lemede e na região de Ourentã (Folha 19-A, Cantanhede; esc. 1/50.000, Serv. Geol de Portugal; BARBOSA et ai, 1987-88) e ainda na «plataforma de Amoreira da Gândara - Febres» (Folha 16-C, Vagos; esc. 1/50.000, Serv. Geol. Portugal; вARBosa et ai, 1981). A sul do Mondego, a semelhança está com as Areias de Marinha das Ondas (SOARES \& REIS, 1984; MARQUES, 1997) que se prolongam mais para sul, para a região de Monte Redondo. Facto a assinalar em todos os areeiros que conhecemos abertos nestes diferentes afloramentos, prende-se com a existência de um (?) horizonte com clastos de argilito plástico, cinzento e/ou amarelo pálido e rico em caulinite.

Deformadas, como bem se demonstra no mapa geológico de Cantanhede (BARBosa et ai, 1988), as Areias de Arazede apresentam mais acentuada variação de fácies na região de Arazede - Amieiro, onde a espessura ronda os $16 \pm 2 \mathrm{~m}$ e o entrecruzado tem polarizações dominantes para S-SW.

Mas se a plataforma de Arazede declina normalmente para os quadrantes W-NW, com altitudes a variarem entre os 100 e $70 \mathrm{~m}$, as Areias de Cantanhede (BARBOSA et ai, 1988) compõem a plataforma de Cantanhede-Mira (CARVALHO, 1964) que mergulha suavemente para ocidente, passando de altitudes entre 70 a $50 \mathrm{~m}$.

Mais a sul, no confronto com a Serra da Boa Viagem, afloram as Areias de Quiaios (SOARES et ai, 1992, 1993; MARQUES, 1997) consideradas como equivalentes daquelas outras de Cantanhede (BARBOSA et ai, 1988). Sobrepostas por falha pelos calcários margosos e margas do Liásico (MARTINS, 1949; CARVAlho, 1952; RIbeiro, 1988; cabral, 1993), em areeiro aberto ao $\mathrm{Km} \mathrm{8,2} \mathrm{da} \mathrm{E.M.} \mathrm{de} \mathrm{Quiaios} \mathrm{para} \mathrm{a}$ Serra, elas correspondem essencialmente a arcosarenitos finos a grosseiros, levemente micáceos, submaturos a imaturos, compactos a subcompactos, acastanhados, entrecruzados e com lentículas de seixo e calhau (12 $\pm 3 \%)$ redondo a subredondo, de esfericidade baixa dominante. Em descontinuidade sobre elas desenvolve-se um corpo de subarcosarenito fino a muito fino, micáceo, maturo, esbranquiçado e com estruturação oblíqua de baixo ângulo. Com raro areão e seixo disperso, elas aproximam-se do subarcosarenito fino a muito fino, maturo, micáceo com estruturação oblíqua de baixo ângulo e esbranquiçado que ocorre a norte da Carapinheira, na região de 
Casal de Areia - Fonte Quente - Fonterma e cartografada como «depósito eólico de cobertura» (SOARES, 1966), ou ainda como «areias hidro-eólicas (Ae)» (BARBOSA et al., 1988). O seu carácter micáceo distingue-as das Areias de Tentúgal que, e ao longo do Mondego, se sobrepõem aos depósitos de terraço (CARVALHO, 1950 ; SOARES, 1966). Estas aproximamse das Areias da Gândara de CARVALHo (1950; 1952; 1964 - Riss?), onde se poderão incluir também as Areias de Cavaleiros - Mourelos (CARVALHO, 1951; SOARES, 1966) que, e na concepção de bARBOSA et al. (1988), foram associadas, em parte, às Areias hidro-eólicas.

É imediato o constatarmos que, também aqui, se colocam diversos problemas, sobretudo os associados a uma mais correcta identificação dos depósitos. Além disso, subsiste sempre a sensação de recorrência dos processos de eolização no contexto da evolução das paisagens, em especial a partir do Depósito de Tentúgal-Gabrielos e do Depósito da Murtinheira (= praia de Murtinheira; SOARES et al, 1993), no Cabo Mondego. Contudo, estamos em crer que um tempo fundamental terá sido a partir do Würm, com desenvolvimento da plataforma litoral (DIAS, 1985, 1987) e concretização de condições periglaciares (CARVALHO, 1954, 1964; DAVEAU, 1973, 1977, 1986; COUDÉ-GAUSSEN, 1981), como parecem testemunhar as interstratificações observadas no Ortoconglomerado de Vale da Anta (SOARES et al, 1993), com identificação a depósitos tipo «grèze». Em suma, as Areias de Gândara, de acordo com a definição de CARVALho (1964), seriam dum Plistocénico superior - Holocénico.

Quanto às Areias de Tentúgal, localmente deformadas por fracturação subparalela com o eixo da «flexuração» do Mondego para sul, entre a Rib." de Ançã e a Serra de Montemor (SOARES et al, 1986), poderão ser mais antigas, mas ainda no quadro do Plistocénico Superior.

Contudo, reconhecemos ser condição especial ao equacionamento de todo este problema, o próprio desenvolvimento das serras da Boa Viagem e Alhadas, ajustadas ao jogo da já hoje denominada falha de Quiaios, com «inversão tectónica muito recente [...], em falha normal, com abatimento relativo do bloco a sul» (CABRAL, ob. cit., p. 230). Esta hipótese é ainda sustentada pelo basculamento para norte do Depósito da Murtinheira.

$\mathrm{Na}$ frente ocidental da Serra da Boa Viagem, no Cabo Mondego, hoje já quase totalmente modificado pelas pedreiras em laboração, desenham-se ainda dois níveis de «praias levantadas», a altitudes de $10 \pm 2 \mathrm{~m}$ e $100 \pm 5 \mathrm{~m}$ respectivamente. Para qualquer delas é possível restituir o traçado das antigas falésias conjugadas, sobretudo a relativa ao Depósito $d a$ Murtinheira, a «praia» mais baixa e cuja altitude passa de cerca de $10 \mathrm{~m}$ junto à Fábrica, para pouco mais de $5 \mathrm{~m}, 2 \mathrm{Km}$ a Norte. Fossilizando-a parcialmente estão os fanglomerados heterolíticos, colmatados pelos Depósitos vermelhos do Cabo Mondego (CARVALHO, 1954, 1964; SOARES et al, 1993; ALMEIDA, 1995; MARQUES, 1997). É muito possível que ela corresponda, de um modo geral, ao nível de praia bem desenvolvido entre o pontal do Sítio da Nazaré e a foz do Mondego e que, por deformação, declina sectorialmente para norte, passando de $15 \pm 3 \mathrm{~m}$ para 5-8 m. Neste sentido, ela poderá corresponder ao Plistocénico Superior (Tirreniano II-III?; ZBYSZEWSKI, 1958; TEIXEIRA, 1979), talvez ao Riss-Wurm (SOARES etal, 1993).

A altitudes de $100 \pm 5 \mathrm{~m}$ desenvolve-se, localmente, a sucessão areno-conglomerática, fossilífera do Depósito do Farol (MARTINS, 1949; ZBYSZEWSKI, 1959; A LMEIDA, 1995; soARES et al, 1993). Cerca de $93 \%$ dos fósseis até hoje recolhidos repartem-se pela Patella vulgata (Lin.), Littorina littorea (Lin.) e Nucella lapillus (Lin.), sendo esta última dominante. Uma tal associação, tradutora duma zona mediolitoral, é hoje característica de águas mais frias da Europa ocidental. Em suma, com fácies distinta de todos os outros depósitos quaternários do Baixo Mondego, estamos em crer que ele poderá representar um episódio regressivo equivalente ao Maghrebiano superior de Marrocos (BREBION, 1979) ou seja, a um Plistocénico inferior a médio, porque não do Emiliano mediterrânico. Se assim for demonstrado, então ele será mais antigo que as Areias de Cantanhede e contemporâneo, ou mesmo mais antigo que as Areias de Arazede.

Em suma, a figura 4 dá-nos conta dos níveis fundamentais de depósitos quaternários do Cabo Mondego, bem como aquele outro areno-pelítico, micáceo, submaturo e castanho (Depósito da Bandeira; in ALMEIDA, 1995), semelhante às Areias de Cordinha e associado à superfície culminante da Bandeira $(258 \mathrm{~m})$.

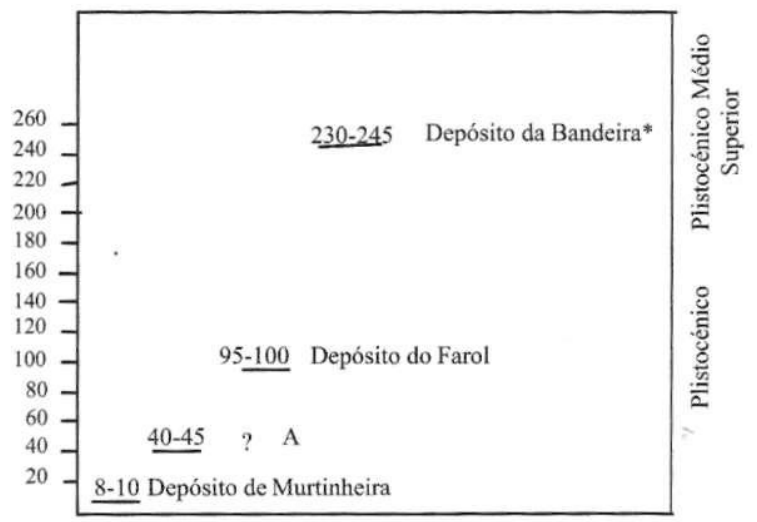

Fig. 4 - Depósitos da Serra da Boa Viagem (Cabo Mondego). A - Resto de depósito na vertente a W do Farol (*-Almeida, A. C., 1995).

Fig. 4 - Serra da Boa Viagem deposits (Cape Modego). A - Deposit remnant in the slope to the west of the lighthouse. 
Um outro problema que sempre tem ressaltado no ordenamento dos depósitos quaternários no espaço do Baixo Mondego é o dos tufos calcários, sobretudo os de Condeixa e Ançã, os de maior expressão volumétrica. Nos Tufos de Condeixa é já clássico o perfil descrito por CHOFFAT (1895) e efectuado junto ao Salgueiro, na confluência da Rib." de Condeixa-a-Velha com o Rio dos Mouros.

Dum modo geral, e talvez mesmo com fundamento nas observações de Choffat, todos os autores têm reconhecido para os tufos uma organização altimétrica (ZBYSZEWSKI, 1958 ) cuja individualização proposta por MENDES (1974) e, até certo ponto aceite por CUNHA (1990), tende para uma leitura convergente com os níveis dos «terraços fluviais» admitidos por SOARES (1966). A verdade porém é que os tufos em Condeixa e Cernache, com aplanamentos a cotas de 100-110 m, declinam para W e NW, atingindo, sem rupturas, altitudes de $70 \mathrm{~m}$, quando não mesmo de 60-50 m. Contudo, e neste sentido, os Tufos deAvenal constituem-se em manchas descontínuas a cerca de $50 \mathrm{~m}$ de cota e desligados realmente do corpo fundamental de Condeixa e Cernache. A ocidente de Cernache, na região da Barroca, tufos idênticos aos do Avenal e a cotas cerca dos 50-60 m, parecem embutidos (?) naqueles outros de Cernache.

Ao ser assim, temos de admitir a organização dos tufos por dois corpos fundamentais a altitudes distintas, os Tufos de Condeixa que se estendem por Condeixa-a-Velha, Condeixa-a-Nova, Eira Pedrinha, Orelhudo, Casconha e Cernache e os Tufos de Avenal com manchas fundamentais na Barroca, Avenal, Quinta da Ventosa e Alqueves, na rede hidrográfica da Ribeira de Cernache.

Recentemente, e para os Tufos de Condeixa, foram reconhecidos quatro grupos fundamentais de fácies (SOARES et ai, 1997): (1) conglomerados heterométricos e de tendência polimítica $(\mathrm{Cg})$; (2) pelitos mais ou menos tufosos, amarelados ou acinzentados e mais ou menos ricos em helicídeos (P); (3) tufos de acumulação ricos em restos de plantas (Ta); e (4) tufos esparríticos em cortina e/ou em cascata (Tc).

$\mathrm{Na}$ zona do Salgueiro, na margem direita da Rib. de Condeixa-a-Velha, na confluência com o Rio dos Mouros, há, na base da formação, corpos lenticulares de conglomerados grosseiros polimíticos, submaturos a imaturos e compondo cerca de $50 \%$ da sequência da base. Se no corpo conglomerático da base os calhaus de quartzo+quartzito totalizam cerca de $75 \%$, para o segundo corpo, separado do primeiro por cerca de $2 \mathrm{~m}$ de pelito tufoso amarelado, localmente com corpos areno-tufosos laminados, são os calhaus de calcário, quase sempre com coroa microsparrítica acastanhada, que chegam a perfazer $70 \pm 20 \%$ da população. Ambos os corpos desaparecem para o Salgueiro, enquanto, ao longo da margem direita do Rio dos Mouros, eles não só se confundem, como diminuem de espessura. No Salgueiro e Eira Pedrinha a fácies conglomerática da base é constituída essencialmente por fragmentos de corpos tubulares a que se associam numerosas concreções subesféricas a subovóides (oncólitos). Fácies semelhante e sempre associada a matriz arenopelítica cinzenta, ocorre, localmente, na base do Tufo de Avenal.

No Tufo de Ançã e na zona do cemitério, a base é de conglomerado heterométrico, calclitítico e com raros calhaus de quartzo, quartzito e xisto $(<10 \%)$. Não detectado na margem direita da ribeira, na zona de S. Bento, a sua espessura máxima ronda o metro.

Em suma, e para o Tufo de Condeixa destacamos: (1) a presença de calhaus de tufo (c. 10\%) no corpo calclitítico superior; (2) a equivalência com a C.2 do perfil descrito por CHOFFAT (1895) e na base da qual foi encontrado um fragmento de molar de Elephas antiquus (Fale \& Cant) (CARDOSO, 1993).

A fácies pelítica, por vezes rica em fracção arenosa $(30 \pm 8 \%)$ cinzenta e carbonatada (8 a 20\%), domina essencialmente nas áreas de Condeixa-a-Nova e Eira Pedrinha onde os corpos lenticulares, ricos em gastrópodes (Lymnaea, Oxyloma, Oxychilluse Hippeutis; Cepaea, Candidula, Theba e Rymina) chegam a apresentar $3 \mathrm{~m}$ de espessura máxima. Em alguns destes corpos há pequenas lentículas plano convexas de tufo de acumulação rico em restos de plantas subparalelas com a estratificação.

$\mathrm{Na}$ base da unidade, por vezes associado às fácies conglomeráticas, os pelitos são amarelos, carbonatados, com helicídeos e, localmente com crostas centimétricas de calcite macrospática em paliçada, ou então com laminas microconcreciondas de aspecto mamelado.

A camada C3 do perfil descrito por CHOFFAT ( $p b$. cit.) e onde foram encontrados, para além de helicídeos, restos de Hippopotamus incognitus Faure (CARDOSO, ob. cit.), deve corresponder ao topo do conjunto essencialmente pelítico do perfil da zona vestibular da Rib." de Condeixa-a-Velha, sob a unidade tufosa p.d..

As fácies tufosas (travertínicas quando mais endurecidas, menos vacuolares e por vezes laminadas) apresentam-se com geometrias e estruturas muito diversas. Dum modo geral e para o Tufo de Condeixa, dominam as fácies vacuolares ricas em restos de vegetais, normalmente subparalelos com a estratificação (tufos de acumulação s.s.) e amareladas. A elas associam-se corpos de tufos tubíferos, com os tubos subverticais, de secções circulares, quando não poligonais e então com estriação vertical interna (tufos de tubos). No Tufo de Avenal há tufos de tubos em que estes chegam a ter dois a três centímetros de diâmetro e constrições transversais.

Não raras vezes ocorrem, nas fácies de acumulação, corpos de diversos desenvolvimentos, por vezes mesmo subverticais, de tufo felpudo, construído por uma rede mais ou menos apertada de filetes maciços, subeireulares e escamosos (tufo musgoso). Esta 
fácies associa-se frequentemente às sequências de tufos em cascata, ou de enchimento «espeleotémico».

Tanto no Tufo de Avenal, como também no de Ançã, a fácies tufosa dominante é esbranquiçada e pulverulenta, recortada por laminas de acumulação centimétricas e irregulares. No Avenal esta fácies interstratifica com pelitos acinzentados, desenhando corpos de secção transversal decamétrica, plano-convexos e com eixo N 030 a 050.

Em Condeixa-a-Velha e Conimbriga há tufos compactos, cinzentos, com helicídeos e que foram explorados tanto para o fabrico de mós, como, mais tarde, como «pedra de ornamentação». A sua estrutura é muito variada, destacando-se não só discretos corpos tubulares, como faixas centimétricas, microlaminadas, onduladas e acompanhando quase sempre corpos de acumulação ou conglomeráticos (oncolíticos).

Finalmente, os tufos em cortina e/ou em cascata, complexos, foram identificados não só na organização espeleotémica desenhada no seio da própria fácies Ta, como ainda na margem direita do Rio dos Mouros, onde laminas decimétricas envolventes e onduladas declinam para o vale, cobrindo, localmente, lapiás abertas nos calcários do substráete No enchimento de cavernas há cortinas centimétricas, onduladas, por vezes zebradas e sempre associadas a outras fácies de tufo, quando não a conglomerados calclitíticos, heterométricos e com oncólitos.

A análise dos significados paleo-ambientais das fácies tufosas é difícil e isto porque ainda nos escapam não só informações paleobiológicas, como também outras susceptíveis de traduzirem a «complicada» trama das suas dependências genéticas. A uma outra escala, elas reflectirão sempre a dependência com o hidrossistema cársico do Maciço de Sicó e das serras de Avessada e S. Domingos, horst cujas falhas orientais condicionam as exsurgências de Alcabideque, Vila Nova e Olho Meirinho, aquelas que hoje aparentam maior intimidade com os tufos (MENDES, 1974). Mas também não olvidamos as interdependências com as próprias reorganizações das redes hidrográficas, sobretudo na consideração de um «pré-Rio dos Mouros» e sua consequente captura e desenho do canhão de Conimbriga (CUNHA, 1990).

De um modo geral e para o Tufo de Condeixa, a evolução prende-se ao ordenamento geral $\mathrm{Cgp}>\mathrm{Cgc}>$ $\mathrm{Pa}>\mathrm{Ta}>\mathrm{Pc}$ ou seja, dentro dum sistema fluvial, à transposição duma base activa de enchimentos de canal, para ambientes paludosos com canais pouco activos e divagantes, onde condições essencialmente bioquímicas orientaram a precipitação dos carbonatos. A tufização ter-se-á então desenvolvido até um óptimo, a partir do qual se produziu degenerescência das condições e espraiamento consequente das fácies pelíticas cinzentas. Esta fase terminal é mais evidente nas áreas de Condeixa-a-Nova e Eira Pedrinha, ligada especialmente à drenagem da Rib. de Cernache.
Seja como for, a tufização parece-nos associada a: (1) criação de um espaço de acomodação entre o horst a oriente das serras calcárias de Avessada e S. Domingos e uma linha de relevos de condicionante estrutural (falhas N020-40) e hoje praticamente incaracterizada e posta a cerca de $4 \mathrm{~km}$ a poente das serras calcárias; (2) instalação de condições susceptíveis de propiciarem o desenvolvimento diferenciado dum coberto vegetal (CARDOSO, ob. cit.); (3) transformação das condições hidrográficas suficientes à sustentação duma fase «degenerativa» da tufização, com aumento da entrada de terrígenos no sistema. Neste esquema geral e por isso mesmo simples, subsistem reparos que só uma cronologia fina poderá ajudar a ultrapassar. Temos, por evidente, que o Tufo de Condeixa não é todo da mesma idade, com tufização a ter características polifásicas. É muito possível que, e neste contexto, os tufos em Condeixa-a-Velha e Conimbriga sejam, dum modo geral, mais velhos que os de Condeixa-aNova, Eira Pedrinha e Cernache. O Tufo de Avenal poderá ser contemporâneo da reorganização da rede hidrográfica da Rib. de Cernache e aproximar-se, pelo menos em parte, da fase «degenerativa» anteriormente referida. Por sua vez e para o Tufo de Ançã o problema não goza de informação capaz de sustentar equivalência com qualquer das fases apontadas para o Tufo de Condeixa. Ele desenvolve-se na consequência da evolução da Rib. de Ançã e assenta, localmente, sobre conglomerado que traduz não só enchimento de pequenos canais, como desenvolvimento local de pequenas barras longitudinais.

No que concerne à cronologia do Tufo de Condeixa e pesados que foram os argumentos avançados (CUNHA, 1990; SOARES et ai, 1997), temos admitido: (1) para a base uma idade provável do Siciliano (Mindel) de acordo com CARDOSO (ob. cit. ), talvez próxima, ou mesmo um pouco mais antiga que os tufos de Santiago de Cacém, datados de 329 e $383 \mathrm{Ka}$ (GAIDA \& RADTKE, 1983). Esta idade e segundo GOMES (inf. oral) parece consequente com a análise dos resultados paleomagnéticos que poderão compatibilizar-se com o criptocrono de polaridade inversa (493 - $504 \mathrm{Ka})$, no Crono Normal de Brunhes. (2) A fase superior, essencialmente pelítica, será já e em grande parte (?) holocénica, talvez a rondar os $2 \mathrm{Ka}$, pela ocorrência, no seu seio, de restos arqueológicos romanos. Contudo, não podemos esquecer a ocupação da gruta de Eira Pedrinha, aberta em tufo de acumulação rico em restos de plantas, por volta dos $4 \mathrm{Ka}$ (CORREIA \& TEIXEIRA, 1949).

É imediato, pelo menos disso temos consciência, a falta de argumentos cronológicos suficientes ao suporte das propostas de ordenamento apresentadas. Este aspecto é tanto mais relevante quanto é certo haver um quadro de fracturação a afectar diversas das unidades identificadas, sobretudo as tidas por mais antigas. Não se pode pois estranhar as reservas com que temos avançado algumas equivalências. Contudo, 


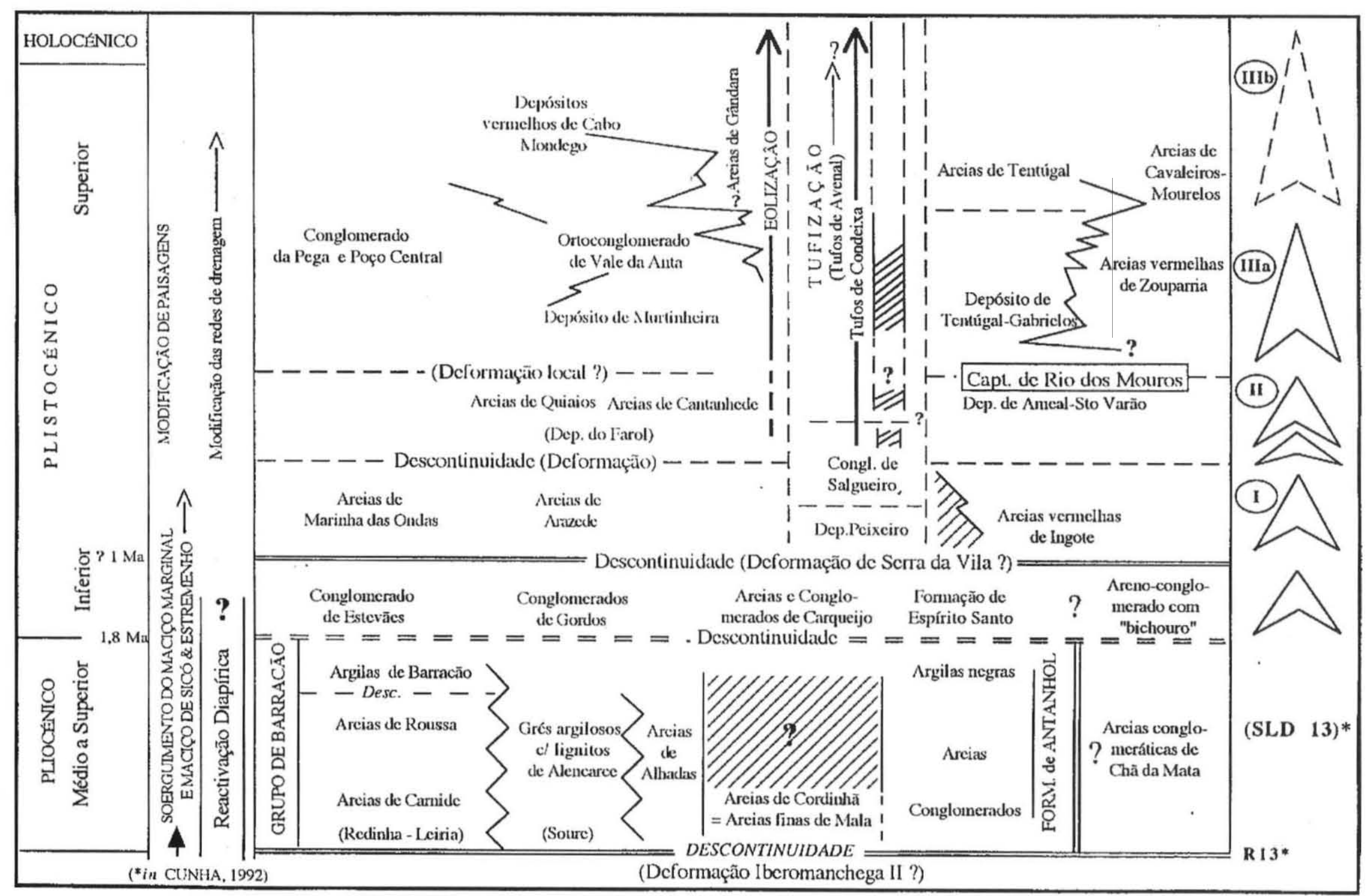


estas indefinições não têm impedido a organização de quadros síntese, cujas leituras só são possíveis na abrangência das hipóteses aventadas. É ainda dentro destes pressupostos que o Quadro I deve ser lido. Por ele procuramos um modelo de prováveis equivalências, apoiados, fundamentalmente em ideias já anteriormente desenvolvidas (SOARES et. ai, 1997; SOARES, no prelo)

B IB LIOGR A FIA

ALMEIDA, A. C. (1992) - Os depósitos superiores da Serra da Boa Viagem e seu significado. Cadernos de Geografia, IEG, Coimbra, 9, p. 151-162

ALMEIDA, A. C. (1995) - Dunas de Qidaios, Gândara e Serra da Boa Viagem. Uma abordagem ecológica da paisagem, Tese de doutoramento, Faculdade de Letras, Universidade de Coimbra, $305 \mathrm{p}$.

ALMEIDA, A. C; SOARES, A. FERREIRA; CUNHA, LÚCIO \& MARQUES, J. F. (1990) - Proémio ao estudo do Baixo Mondego. Biblos, Coimbra, vol. LXVI, p. 17-47.

BARBOSA, B. P. (1981) - Notícia Explicativa da folha 16-C (Vagos) da Carta Geológica de Portugal na escala 1:50000, Serviços Geológicos de Portugal, Lisboa.

BARBOSA, B. P. (1983) - Argilas especiais de Barracão-Pombal. Prospecção, sondagens e cálculo de reservas. Estudos Notas e Trabalhos, Serviços de Fomento Mineiro, Porto, 25 (3-4), p. 193-212.

BARBOSA, B. P. (1995) - Alostratigrafia e Litostratigrafia das Unidades Continentais da Bacia Terciária do Baixo Tejo. Relações com o eustatismo e a tectónica, Dissertação de Doutoramento, Faculdade de Ciências, Universidade de Lisboa, $253 \mathrm{p}$.

BARBOSA, B. P., SOARES; A. F, ROCHA, R. B., MANUPELLA, G \& HENRIQUES, M. H. (1988) - Notícia Explicativa da folha 19-A (Cantanhede) da Carta Geológica de Portugal na escala 1:50000, Serviços Geoógicos de Portugal, Lisboa, 46 p.

BREBION, Ph. (1979) — Étude biostratigraphique et paléoécologique du Quaternaire marrocain. Annales de Paléontologie (Invertébrés), Paris, 65 (1), p. 1-42.

CABRAL, J. (1993) - Neotectónica de Portugal Continental. Dissertação de Doutoramento, Faculdade de Ciências, Universidade de Lisboa , $435 \mathrm{p}$

CACHÃO, M. P. A. (1990) - Posicionamento biostratigráfico da jazida pliocénica de Carnide (Pombal). Gaia, Lisboa, 2 , p. $11-16$.

CACHÃO, M. P. A. (1995) - Utilização de nanofósseis calcários em Biostratigrafia, Paleoceanografia e Paleoecologia. Aplicações ao Neogénico do Algarve (Portugal) e do Mediterrâneo Ocidental (ODP 653) e a problemática do Coccolithus pelagicus, Dissertação de Doutoramento, Faculdade de Ciências, Universidade de Lisboa, 356 (+VIH)p.

CARDOSO, J. L. (1993) - Contribuição para o conhecimento dos grandes mamíferos do Plistocénico superior de Portugal. Câmara Municipal de Oeiras.

CARVALHO, A. M. G. (1972) — Caracterização sedimentológica dos depósitos Plio-Plistocénicos da região de Leiria, Revista da Faculdade de Ciências, 2." Sec., C - Ciências Naturais, Lisboa, vol. XVII, p. 197-206.

CARVALHO, G. S. (1948) - Depósitos detríticos pliocénicos dos arredores de Coimbra. Revista da Faculdade de Ciências da Universidade de Coimbra; XVII, p. 157-176.

CARVALHO, G. S. (1949) — Les dépôts des terrasses et la Paléogeographie du Pliocène dans la Bordure Meso-cenozoique Occidentale du Portugal (entre Vouga e Mondego). Revista da Faculdade de Ciências da Universidade de Coimbra, vol. XVIII, p. 34-58.
CARVALHO, G. S. (1950) - Contribuição para a interpretação da origem dos depósitos plio-plistocénicos da Orla Meso-cenozoica ocidental (região entre o Vouga e o Mondego). Memórias e Notícias, Rev. Mus. Lab. Min. e Geol. Univ. Coimbra, 28. p. 26-48.

CARVALHO, G. S. (1951) - A geologia do Baixo Mondego nos arredores de Coimbra (Estado actual do seu conhecimento), Memórias e Notícias, Rev. Mus. Lab. Min. e Geol. Univ. Coimbra, 29, p. 1-33.

CARVALHO, G. S. (1952) — Les dépôts détritiques plio-pleistocènes et la morphologie de la «Gândara» au Nord de la Serra da Boa Viagem (Portugal). Revue de Géomorphologie Dynamique, Paris, 6, p. 275-294.

CARVALHO, G. S. (1953) — Les époches d'éolization du Pleistocène dans la Bordure Occidentale Meso-cenozoique du Portugal, Memórias e Notícias, Rev. Mus. Lab. Min. e Geol. Univ. Coimbra, 33.

CARVALHO, G. S. (1954) — A Gândara (Portugal) e as Landes da Gasconha (França). Memórias Notícias,Publ. Mus. Min. Geol. Univ. Coimbra, 37, Coimbra, 19p.

CARVALHO, G. S. (1954) — Sur les dépotsà galets calcairesdu Bassin du Mondego et les sables de la Gândara (Portugal). Revue de. Geomorphologie Dynamique, Paris, 5, p. 193-203.

CARVALHO, G. S. (1964) — Areias da Gândara (Portugal) - uma formação eólica quaternária. Pub! Mus. Lab. Min. Geol. Fac. Ciências, 4." sér. Porto, 81, 32p.

CARVALHO, G. S. (1981) — Uma metodologia para análise dos depósitos do Quaternário. Arqueologia, Grupo Estudos Arqueológicos, Porto, 4, p. 50-63.

CARVALHO, M. (1998) - Estudo preliminar do Plio-Quaternário do Baixo Mondego. Sector de MonteRedondo - Pombal, Comunicações, Inst. Geol. e Mineiro; Actas do V Congresso Nacional de Geologia, Lisboa, t. 84, fs. 1, p. A-173-176.

CHOFFAT, P. (1895/ 98) — Note sur les tufs de Condeixa et la découvert de l'Hippopotome en Portugal. Com. Dir. Trab. Geol. Portugal, Lisboa; t. III, p. 1-12.

CORREIA, A. M. \& TEIXEIRA, C. (1949) — Jazida pré-histórica de Eira-Pedrinha (Condeixa). Direcção Geral de Minas e Serviços Geológicos, Serviços Geológicos de Portugal, Lisboa.

COUDÉ-GAUSSEN, G (1981) — Les Serras da Peneda et do Gerês. Étude Geomorpnologique, Memórias do Centro de Estudos Geográficos, Lisboa, 5, $254 \mathrm{p}$.

CUNHA, L. (1988) - As serras calcárias de Condeixa-Sicó-Alvaiázere. Estudo de Geomorfologia. Tese de doutoramento, Faculdade de Letras, Universidade de Coimbra, 329 p.

CUNHA, P. M. R. R. P (1992) - Estratigrafia e sedimentologia dos depósitos do Cretácico superior e Terciário de Portugal Central, a Leste de Coimbra. Dissertação de Doutoramento, Faculdade de Ciências e Tecnologia, Universidade de Coimbra, $262 \mathrm{p}$.

DAVEAU, S. (1973) — Quelques examples d'évolution quaternaire des versants au Portugal, Finisterra, Lisboa, 15, p. 5-47.

DAVEAU, S. (1985/86) - Les Bassins de Lousã et d'Arganil. Recherches géomorphologiques et sédimentologiques sur le Massif Ancien et sa couverture à l'Est de Coimbra. Vol. I Le Bassin Sédimentaire; Vol. II - L'Évolution du Relief (coll. de P. Birot et O. Ribeiro). Memórias do Centro de Estudos Geográficos, Lisboa, 8, 450 p.

DAVEAU, S. (1993a) - Terraços fluviais e litorais, in G. S. CARVALHO, A. B. FERREIRA e J. C. SENNA-MARTINEZ (eds.), O Quaternário em Portugal, balanço e perspectivas, Lisboa, Colibri; p. $17-28$.

DAVEAU, S. (1993b) - Evolução quaternária da plataforma litoral. in G. S. CARVAlHO, A. B. FERREIRA e J. C. SENNA-MARTINEZ (eds.), O Quaternário em Portugal, balanço e perspectivas, Lisboa, Colibri, p. 30-41.

DAVEAU, S. (s/d) - L'évolution géomorphologique quaternaire au Portugal - Principaux aspects et problèmes posés par son études. Rech. Franc. Quaternaire hors de France, 10e Congr. Int. INQUA, Birmigham (Août, 1977), Supp. Bulletin del'AFEQ, Paris, p. 11-21. 
DIAS, J. M. A. (1985) - Registos da migração da linha de costa nos últimos 18000 anos na plataforma continental portuguesa setentrional. Actas, I Reunião do Quaternário Ibérico, Lisboa, vol. I, p. 281-295.

DIAS, J. M. A. (1987) — Dinâmica sedimentar e evolução recente da plataforma continental portuguesa setentrional. Dissertação de Doutoramento, Faculdade de Ciências da Universidade de Lisboa, $384 \mathrm{p}$

DINIS, P. A. (no prelo) - «Arquitectura do registo sedimentar que acompanha a plataforma litoral na margem esquerda do rio Cértima (Centro-Oeste de Portugal)».

DINIZ, F. (1984) - Apports de la palynologie a la connaissance du Pliocène portugais. Rio Maior: um bassin de référence pour l'histoire de la flore, de la végétation et du climat de la façade atlantique de l'Europe Méridionale, Thèse, Univ. Se. Tech. Languedoc; Montpellier; $230 \mathrm{p}$.

GAIDA, R. \& RADTKE, U. (1983) - Datation de tufs calcaires quaternaires du Baixo Alentejo par les méthodes Th/U e ESR. Finisterra, Lisboa, XVIII, 35, p. 107-111.

MARQUES; J. F. (1997) — O significado dos depósitos quaternários do Baixo Mondego. Uma retrospectiva. Seminário «O Baixo Mondego», Coimbra, p. 21-39;

MARTINS, A. F. (1949) — Le Centre Littoral et le Massif Calcaire d'Estremadura (Livret - Guide de l'excursion B). Congrès International de Géographie, Lisboa, 96 p.

MENDES, A. G. (1974) - Os tufos de Condeixa - morfologia da área dos tufos de Condeixa, Dissertação de Licenciatura em Geografia, Faculdade de Letras da Universidade de Coimbra, $173 \mathrm{p}$.

REBELO, F. M. S. (1986) - Contribuição para o conhecimento do modelado periglaciar de baixa altitude em Portugal^ctas $d a$ I Reunião do Quaternário Ibérico, Lisboa, vol. I, p.141-151.

REBELO, F. M. S. (1993) - A apresentação do quaternário na cartografia geológica e geomorfológica portuguesa, in G. S. CARVALHO, A. B. FERREIRA e J. C. SENNA-MARTINEZ (eds.) O Quaternário em Portugal, balanço e perspectivas, APEQ; Colibri, Lisboa, 295 p.

RIBEIRO, A. (1988) - A tectónica alpina em Portugal, Geonovas, Lisboa, 10, p. 9-11.

RIBEIRO, O. \& PATRÍCIO; A. (1943) - Nótula sobre os terraços do Mondego nos arredores de Coimbra, Assoe. Port. Prog. das Ciências - 4." Congresso, Porto; V, 4. "Secção-Ciências Naturais, p. 188-194.

ROCHA, R.; MANUPELLA, G.; MOUTERDE, R.; RUGET, CH.; ZBYSZEWSKI, G. (1981) - Notícia explicativa da Folha 19-C, Figueira da Foz. Carta Geológica de Portugal, escala 1/50000, Serviços Geológicos de Portugal, Lisboa, 126 p.

SOARES, A. F. (1966) — Estudo das formações pós-Jurássicas da região de entre Sargento-Mor e Montemor-o-Velho (margem direita do rio Mondego). Memórias e Notícias, Rev. Mus. Lab. Min. e Geol. Univ. Coimbra, 62, 343p.

SOARES, A. F. (1990) - Apontamentos sobre a Geologia de Coimbra. Livro de Homenagem a Carlos Romariz, Lisboa, p. 310-331.

SOARES, A. F. (1993) - O tempo das caretas (Pretexto para algumas ideias). Actas da III Reunião do Quaternário Ibérico, Coimbra, p. 363-375.

SOARES, A. F. (no prelo) - Reflexões sobre os tempos de carsificação dos maciços calcários de Sicó, Alvaiázere e Estremenho.

SOARES, A. F.; CUNHA, L. \& MARQUES, J. F. (1989) — Depósitos quaternários do Baixo Mondego. Tentativa de coordenação morfogenética. Actas da II Reunião do Quaternário Ibérico, Madrid, p. 803-812.

SOARES, A. F.; CUNHA, L. \& MARQUES, J. F. (1997) — Les tufs calcaires de Condeixa. Présentation générale et encadrement dans le modèle géomorphologique de l'évolution de la région du Bas Mondego (Portugal), Études de Geographie Physique, Tr. 1997 - Suff. au N. ${ }^{\circ}$ XXVI, Col. hispano-français, Univ. de Provence, p. 55-58.

SOARES, A. F.; CUNHA, L., MARQUES, J. F., ALMEIDA, A. C. \& LAPA M. R. (1993) — Depósitos de vertente no cabo Mondego Integração no modelo evolutivo do Quaternário do Baixo Mondego. Actas da III Reunião do Quaternário Ibérico, Coimbra, p. 199-208.

SOARES, A. F.; CUNHA, L.; ALMEIDA, A. C. \& MARQUES, J. F. (1992) - Depósitos quaternários do Baixo Mondego. Estado actual dos conhecimentos e tentativa de coordenação morfogenética. Actas do VI Colóquio Ibérico de Geografia, Publ. Univ. Porto, vol. II, p. 773-782.

SOARES, A. F.; FERREIRA, A. B. \& MARQUES; J. F. (1986) - A evolução geomorfológica e sedimentológica das plataformas litorais entre o Mondego e o Vouga, a margem direita do Baixo Mondego. Comunicações do II Congresso Nacional de Geologia, Lisboa.

SOARES, A. F.; RAMOS, A. M. \& MARQUES, J. F. (1998) - Os depósitos mais recentes da margem direita do Mondego entre Coimbra e Montemor-o-Velho, Cadernos de Geografia, IEG, Coimbra, 17, p. 73-79.

SOARES, A. F.; REBELO, F. M. S. \& MARQUES, J. F. (1985) - O perfil longitudinal do Rio Dueça a jusante de Miranda do Corvo, Actas da 1 Reunião do Quaternário Ibérico, Lisboa, Vol. II, p. 345-353.

SOARES, A. F. \& REIS, R. P. (1984) - Consideraç̃es sobre as unidades litostratigráficas pós-jurássicas na região do Baixo-Mondego, Livro de Homenagem a Orlando Ribeiro, 1. vol., Centro de Estudos Geográficos, Lisboa, p. 183-202.

SOARES, A. F.; ROCHA, R. B. \& MARQUES, J. F. (1985) Contribuição para o estudo geológico de Coimbra, Memórias e Notícias, Publ. Mus. Lab. Min. Geol. Univ. Coimbra, 100 p. 41-71.

TEIXEIRA, C. (1948) — Les dépôts modernes du littoral portugais au Nord de Leiria. Boletim da Sociedade Geológica de. Potugal, Porto, vol. VII (I-II), p. 83-94.

TEIXEIRA, C. (1979) - O Plio-plistocénico de Portugal. Comunicações dos Serviços Geológicos de Portugal, Lisboa, 65 , p. 35-46.

TEIXEIRA, C. \& ZBYSZEWSKJ, G. (1951) - Note sur le Pliocène de la région à l'Ouest de Pombal. Comunicações dos Serviços Geológicos de Portugal, Lisboa, XXXII (I parte), p. 295-302.

TEIXEIRA, C. \& ZBYSZEWSKI, G. (1954) - Contribuition à l'étude du littoral pliocène au Portugal. C. R. 19éme Congr. Géol. Int., Alger; 13, p. 275-284

VANNEY, J. R \& MOUGENOT, D. (1980) - La plate-forme continentale du Portugal et les provinces adjacents : Analyse geomorphologique. Memórias, Serv. Geol. Portugal, Lisboa, 28, 86 p.

ZBYSZEWSKI, G. (1958) - Le Quaternaire du Portugal. Boletim da Sociedade Geológica de Portugal, Porto, vol. XIII (I-II), 227 p.

ZBYSZEWSKI, G. \& TELXEIRA, C. (1949) - Le niveau quaternaire marin de 5-8 mètres au Portugal. Boletim da Sociedade Geológica de Portugal, Porto, Vol. VIII (I-II), p. 1-6.

ZILHÃO, J. (1990) — Le Solutréen du Portugal: Environment, chronologie, industries, peuplement, origines, Les industries à pointes foliacées du Palolithique supérieur européenes, Krakow, 1989; E. R. A. U. L., Liège, 42, p. 485-501. 